\title{
Age-Independent Synaptogenesis by Phosphoinositide 3 Kinase
}

\author{
Alfonso Martín-Peña, ${ }^{1}$ Angel Acebes, ${ }^{1}$ José-Rodrigo Rodríguez, ${ }^{1}$ Amanda Sorribes, ${ }^{2}$ Gonzalo G. de Polavieja, ${ }^{2}$ \\ Pedro Fernández-Fúnez, ${ }^{3 *}$ and Alberto Ferrús ${ }^{1 *}$ \\ ${ }^{1}$ Cajal Institute, Consejo Superior de Investigaciones Científicas, 28002 Madrid, Spain, ${ }^{2}$ Department of Theoretical Physics, Universidad Autónoma, 28049 \\ Madrid, Spain, and ${ }^{3}$ Department of Neurology, University of Texas Medical Branch, Galveston, Texas 77555
}

Synapses are specialized communication points between neurons, and their number is a major determinant of cognitive abilities. These dynamic structures undergo developmental- and activity-dependent changes. During brain aging and certain diseases, synapses are gradually lost, causing mental decline. It is, thus, critical to identify the molecular mechanisms controlling synapse number. We show here that the levels of phosphoinositide 3 kinase (PI3K) regulate synapse number in both Drosophila larval motor neurons and adult brain projection neurons. The supernumerary synapses induced by PI3K overexpression are functional and elicit changes in behavior. Remarkably, PI3K activation induces synaptogenesis in aged adult neurons as well. We demonstrate that persistent PI3K activity is necessary for synapse maintenance. We also report that PI3K controls the expression and localization of synaptic markers in human neuroblastoma cells, suggesting that PI3K synaptogenic activity is conserved in humans. Thus, we propose that PI3K stimulation can be applied to prevent or delay synapse loss in normal aging and in neurological disorders.

Key words: synaptogenesis; Drosophila; PI3K; aging; central complex; locomotion

\section{Introduction}

The number of synapses in the nervous system changes under the influence of a variety of normal physiological factors, including hormonal status (Kretz et al., 2004), activity (Devaud and Ferrus, 2003; Harris et al., 2003), or age (Gan et al., 2003; Rosenzweig and Barnes, 2003; Coggan et al., 2004). Also, cognitive deficits associated with aging or certain pathologies result from widespread synapse loss in brain neurons (Spires and Hyman, 2004). Synaptic loss is currently established as the best neurobiological correlate of the cognitive deficits in Alzheimer's disease (Honer, 2003; Scheff and Price, 2003) and schizophrenia and mood disorders (Kolomeets et al., 2005). Conversely, synapse number does not seem to change with age in the CA1 stratum radiatum of the rat hippocampus, although it is severely reduced in the dentate gyrus (Geinisman et al., 2004). Moreover, excitatory, but not inhibitory, synapses seem to decrease in the prefrontal cortex of aged monkeys (Luebke et al., 2004). These results suggest that synapse loss may be region specific and even neuronal type specific. In this context, modulation of the number of synapses in selected brain

Received March 21, 2006; revised July 26, 2006; accepted Aug. 21, 2006.

This work was supported by Cajal Institute Grant BMC2003/05051 (A.F.). A.M.P. was funded by Spanish Ministry of Education Fellowship BES-2004-3734. We thank G. Morata, E. Hafen, R. Davis, N. Ito, S. Leevers, L. Luo, M. Freeman, and the Bloomington Stock Center for fly strains, E. Buchner and A. Hofbauer for the nc 82 antibody, and R. Wolf for providing the Buridan's arena and the corresponding software. Assistance by C. Hernández-Capitán from the image facility is most appreciated.

P.F.-F. and A.F. contributed equally to this work.

Correspondence should be addressed to Alberto Ferrús, Cajal Institute, Consejo Superior de Investigaciones Científicas, Avenida Dr. Arce 37, 28002 Madrid, Spain. E-mail: aferrus@cajal.csic.es. DOI:10.1523/JNEUROSCI.1223-06.2006

Copyright $\odot 2006$ Society for Neuroscience $\quad 0270-6474 / 06 / 2610199-10 \$ 15.00 / 0$ regions could be an efficient strategy to ameliorate the cognitive decline associated with normal aging or neurological pathologies.

The cellular and molecular mechanisms controlling synapse number in each neuron under particular physiological conditions, however, remain essentially unknown. As a first approximation, the number of synapses that a neuron establishes correlates with its cellular size (Gulyas et al., 1999). Thus, it is justified to explore the role that molecular mechanisms controlling cell size might have on synaptogenesis. In Drosophila, mutations in the tuberous sclerosis complex 2 (TSC2) ortholog gigas lead to a twofold to threefold increase of synapses in sensory neurons (Canal et al., 1994; Acebes and Ferrus, 2001). TSC2 is a negative regulator of signaling pathways downstream of tyrosine kinase receptors (TKRs) that modulates phosphoinositide 3 kinase (PI3K) signaling (Marygold and Leevers, 2002; Inoki et al., 2003). Members of the TKR family include receptors for insulin (InR), epidermal growth factor (EgfR), and neural growth factor, among others. All of these receptors control cell growth, proliferation, and differentiation (Madziar et al., 2005), and their respective signaling pathways include PI3K. Here, we analyzed the synaptogenic activity of a class Ia PI3K that forms heterodimers between a catalytic subunit (Dp110, homolog to human p110) and a regulatory subunit (p60, homolog to human p85) (Cantley, 2002). By counting synapses in abdominal motor neurons and brain projection neurons, we demonstrate that PI3K, along with other components of the InR signaling pathway (Oldham and Hafen, 2003), control cell size, proliferation, and synaptogenesis. We report that the activity of PI3K and the downstream kinase protein kinase B/Akt tightly control the formation and maintenance of synapses in a cell autonomous manner. 


\section{Materials and Methods}

Fly strains. The strains upstream activating sequence (UAS)-InR.Exel and UAS-InR ${ }^{\mathrm{K} 1409 \mathrm{~A}}$ (Exelixis) were obtained from the Bloomington Drosophila Stock Center (Indiana University, Bloomington, IN) (FlyBase, http://flybase.bio.indiana.edu). The following strains were gifts: galactosidase-4 (Gal4)-796 (G. Morata, Centro de Biología Molecular, Madrid, Spain); UAS-glycogen synthase kinase (GSK3) (Bourouis, 2002); UAS-PI3K ${ }^{92 \mathrm{E}}$ and UAS-PI3K ${ }^{92 \text { ED }^{254 A}}$ (Leevers et al., 1996); UASAkt and UAS-dRheb (Radimerski et al., 2002; Stocker et al., 2003); and UAS-EgfR $^{1.7}$ and UAS-EgfR ${ }^{\text {DN }}$ (Freeman, 1996). As reporters, we used green fluorescent protein (GFP) constructs targeted to the cytosol, membrane (Lee and Luo, 2001), nucleus (R. Davis, Baylor College of Medicine, Houston, TX), or synaptic vesicles (Estes et al., 2000). For electron microscopy studies, we used the UAS-HRP as reporter (Watts et al., 2004). All crosses were reared at $25^{\circ} \mathrm{C}$ unless otherwise indicated. The temperature-sensitive form of the Gal4 repressor Gal80 $\left(\mathrm{Gal}_{80}{ }^{\mathrm{ts}}\right)$ construct (McGuire et al., 2003) is active at $17^{\circ} \mathrm{C}$ to inhibit Gal4 and becomes inactive at $30^{\circ} \mathrm{C}$, allowing Gal4 transcriptional activity. Single neuron mosaics were obtained by the heat-shock activation of flippase recombinase (FLP) on animals carrying the construct UAS-flippase recombinase target (FRT)-CD2-FRT-CD8-GFP (Lee and Luo, 2001). Different pulses of FLP were assayed during metamorphosis to achieve a high frequency of single neuron clones.

Histology and immunostaining. For confocal microscopy, females of corresponding genotypes and age were collected and anesthetized on ice. Brains were dissected in $0.1 \mathrm{~m}$ cold phosphate buffer and mounted unfixed in $50 \%$ glycerol in $0.1 \mathrm{M}$ phosphate buffer. Immunostaining of whole mounts or fillet preparation for larval neuromuscular junctions (NMJs) were performed using monoclonal antibodies nc82 (Wagh et al., 2006), anti-HRP (Jackson ImmunoResearch, West Grove, PA), and antiGFP (Invitrogen, Carlsbad, CA) and later visualized with Alexa568 and Alexa488 secondary antibodies (1:500; Invitrogen). For immunostaining cells, cultures were fixed with $4 \%$ paraformaldehyde in PBS and incubated with anti-synaptic vesicle protein 2 (SV2) (1:75; Developmental Studies Hybridoma Bank, University of Iowa, Iowa City, IA). Transmission electron microscopy (TEM) was performed in flies anesthetized on ice, fixed in $0.1 \mathrm{M}$ cacodylate buffer $/ 2.5 \%$ paraformaldehyde $/ 2.5 \%$ glutaraldehyde $/ 0.04 \% \mathrm{CaCl}_{2}, \mathrm{pH} 7.5$, for $3 \mathrm{~h}$ at room temperature, washed in $0.1 \mathrm{M}$ cacodylate buffer, and postfixed with $2 \% \mathrm{OsO}_{4}$ in $0.1 \mathrm{M}$ phosphate buffer $/ 0.02 \% \mathrm{CaCl}_{2} / 2.25 \%$ sucrose. Heads were dehydrated in ethanol series and embedded in Araldite. Blocks were cut on a Reichert Ultracut E ultramicrotome at $2 \mu \mathrm{m}$, and semithin sections were stained with toluidine blue to identify the ellipsoid body (EB). Selected semithin sections were remounted in Araldite and sectioned to ultrathin sections. Ultrathin silver sections $(60-70 \mathrm{~nm})$ were collected on Formvar-coated, single-slot grids and stained with uranyl acetate $(1 \mathrm{~h})$ and lead citrate (15 $\mathrm{min})$. HRP-expressing flies were anesthetized on ice and fixed in $0.1 \mathrm{M}$ cacodylate buffer $/ 0.04 \% \mathrm{CaCl}_{2} / 2 \%$ glutaraldehyde, $\mathrm{pH} 7.5$, for $17 \mathrm{~h}$ at $4^{\circ} \mathrm{C}$. Heads were embedded in $5 \%$ low-melting agarose and cut at $100 \mu \mathrm{m}$ on vibratome. Vibratome sections were incubated $30 \mathrm{~min}$ in streptavidin (SA)-HRP (1:50), $40 \mathrm{~min}$ in trichostatin A (1:20), and $30 \mathrm{~min}$ in SAHRP (1:50), and the DAB reaction was developed by the ABC method (Vector Laboratories, Burlingame, CA). DAB-positive sections containing the ellipsoid body were postfixed and embedded in Araldite, and $60-70 \mathrm{~nm}$ ultrathin sections were obtained as described above. Synapse number was calculated on images from groups of serial sections applying the dissector technique or multiplying EB volume $\times$ average surface density.

Tissue culture and Western blots. Tissue cultures were grown to semicongruency in $10 \%$ fetal bovine serum supplemented DMEM medium. Pharmacological treatments were performed for $90 \mathrm{~h}$ with $50 \mu \mathrm{g} / \mathrm{ml}$ 740Y-P, $5 \mu \mathrm{M} \quad$ LY294002 [2-(4-morpholinyl)-8-phenyl-1(4H)benzopyran-4-one], or $10 \mu \mathrm{M}$ wortmannin (all from Sigma, St. Louis, $\mathrm{MO}$ ), changing the medium every $2-3 \mathrm{~d}$. For Western blots, membranes were incubated with primary antibodies against SV2 (1:5000; Developmental Studies Hybridoma Bank); $\beta 3$-tubulin (1:4000), Akt (1:2000), and P-Akt (1:1000; Cell Signaling Technology, Boston, MA) and developed with an Amersham Biosciences (Arlington Heights, IL) kit after incubation with the secondary antibodies anti-rabbit $\operatorname{IgG}$ and antimouse IgG (1:8000; Bio-Rad, Hercules, CA). Films were scanned and bands quantified with Quantity One software on a Bio-Rad GS800 densitometer.

Image collection and analysis. The preparations for confocal microscopy were observed as whole mounts on a Leica (Heidelberg, Germany) TCS-SP2-AOBS-UV equipped with a motorized inverted microscope (DMIRE2; Leitz, Wetzlar, Germany). Serial optical sections $(512 \times 512$ pixels) were taken at $1 \mu \mathrm{m}$ intervals using $65 \times$ or $100 \times$ objectives. Quantitative analysis and three-dimensional (3D) reconstructions was performed on AMIRA 3.1 (Zuse Institute Berlin, Berlin, Germany), the area of interest being labeled in each file by Image Segmentation Editor. The corresponding segmentation of 3D images was measured to obtain the volume of each sample. For EB volume measurements, images from toluidine blue-stained serial semithin sections were aligned with AMIRA 3.1, and each slice was labeled by Image Segmentation Editor and processed as confocal stacks to obtain volumes. The larval motor neurons were analyzed in single serial confocal sections spaced at $1 \mu \mathrm{m}(1024 \times$ 1024 pixels). All measurements were taken by at least two independent observers using coded material.

Electrophysiology. Recordings were obtained from late third-instar larvae from genotypes Gal4-D42/UAS-PI3K ${ }^{92 E}$ (experimental) and Gal4D42 (control). Larvae were dissected open dorsally and pinned to a Sylgard-coated dish, and their CNS was removed. Dissection and external electrophysiological saline contained the following (in mM): $70 \mathrm{NaCl}$, $5 \mathrm{KCl}, 1.5 \mathrm{CaCl}_{2}, 20 \mathrm{MgCl}_{2}, 10 \mathrm{NaHCO}_{3}, 5$ trehalose, 115 sucrose, and 5 HEPES, pH 7.2. Single-electrode current-clamp or bridge-balanced recordings (SEC-03 amplifier; NPI Electronics, Tamm, Germany) were performed at $18-20^{\circ} \mathrm{C}$ from muscle fibers $\mathrm{F} 6$ and $\mathrm{F} 7$ in abdominal segment A3 using filamented quartz capillaries pulled to a resistance of 20-50 M $\Omega$. Data were low-pass filtered at $0.5 \mathrm{kHz}$ (LPBF-01G; NPI Electronics) and acquired at $10 \mathrm{kHz}$ using custom-built software (Juusola and de Polavieja, 2003) with an interface for National Instruments (Austin, TX) boards (MATDAQ; H. P. C. Robinson). Analysis was performed with custom-built software written in Matlab language (MathWorks, Natick, MA). Spontaneous responses were recorded continuously for $10 \mathrm{~min}$ in each muscle (two muscles per larva, six PI3K and six control larvae). All recordings had a resting potential lower than -60 $\mathrm{mV}$. Spontaneous events [miniature endplate potentials (mepps)] were detected using a threshold of $0.2 \mathrm{mV}$, well above noise (fluctuations $<0.1$ $\mathrm{mV}$, measured outside the muscle), and corroborated by visual inspection. A borosilicate suction pipette (10 $\mu \mathrm{m}$ tip) filled with external saline was used to evoke suprathreshold responses (tested in each muscle to excite both $\mathrm{Ib}$ and Is motor neuron fibers) and obtained at $0.1 \mathrm{~Hz}$ using shocks $(0.1 \mathrm{~ms}, 0.5-3 \mathrm{~V})$ with an isolated stimulator ISO-STIM 01M (NPI Electronics) in 14 PI3K muscles (11 larvae) and 14 control muscles (9 larvae).

Statistical analysis. Morphological data are presented as average \pm SEM from at least three measurements per genotype. Statistical significance was calculated using Student's two-tailed $t$ test (paired two samples for means). Significant differences between compared groups was noted by a single asterisk if $p<0.05$ or better. Electrophysiological data are presented as mean \pm SEM. The Lilliefors test for normality was always performed before application of the Student's $t$ test for statistical significance. The SPSS software (SPSS, Chicago, IL) was used throughout.

\section{Results}

\section{PI3K activity controls synapse number in motor neurons}

Motor neurons produce stereotyped projections in the body wall muscles of the larva, making them a good model to investigate the genetic basis of synapse formation. To determine the role of PI3K signaling in the control of synapse number, we first overexpressed PI3K and Akt in larval motor neurons. The NMJs of muscle fibers F12 and F13 were visualized with anti-HRP antibody to identify neuronal membranes. Synapses were revealed by the monoclonal antibody nc82, which recognizes a CAST (CD3E-associated protein) homolog localized to the presynaptic specialization (Wagh et al., 2006). Larvae overexpressing PI3K 

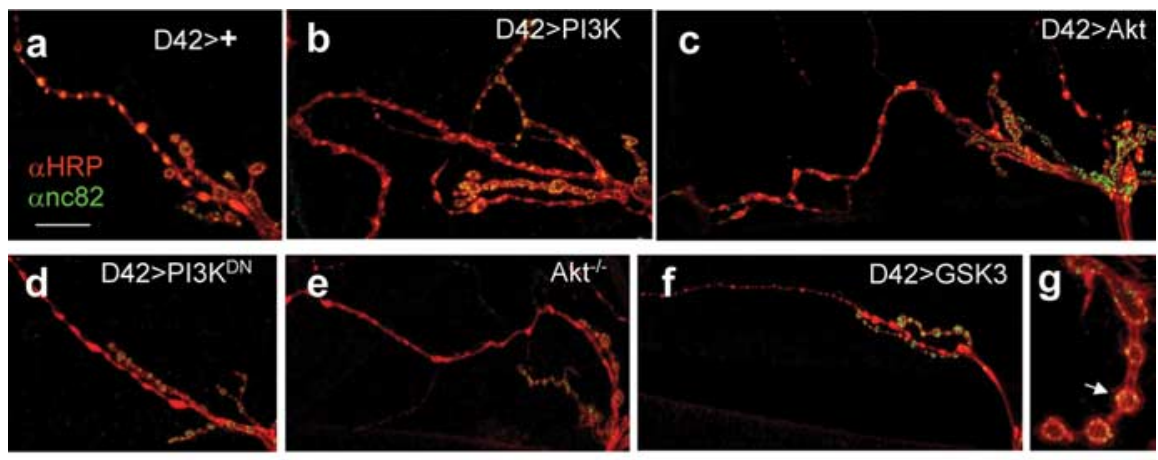

h

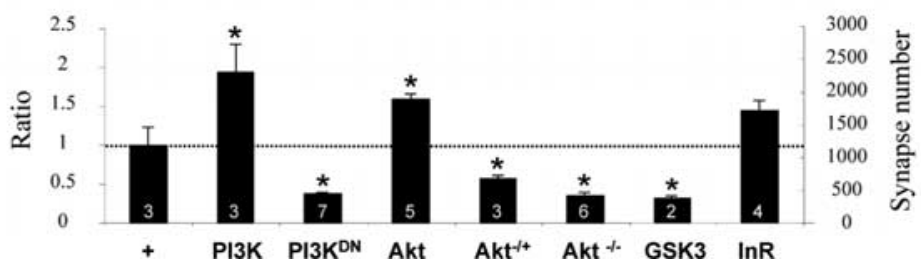

Figure 1. PI3K regulates synapse number in larval motor neurons. $\boldsymbol{a}-\boldsymbol{g}$, Larval neuromuscular junctions of muscle fibers $F 12$ or F13 stained with anti-HRP (red) and the synapse-specific nc82 (green) antibodies in control flies (a; Gal4-D42/ + ) or flies carrying constructs that activate PI3K ( $\boldsymbol{b}, \boldsymbol{g}$; Gal4-D42/UAS-PI3K ${ }^{92 E}$ ), activate Akt ( $\boldsymbol{c}$; Gal4-D42/UAS-Akt), repress PI3K ( $\boldsymbol{d}$; Gal4-D42) UAS-PI3K ${ }^{\text {DN }}$, and activate GSK3 ( $\boldsymbol{f}$; Gal4-D42/UAS-GSK3) or are homozygous mutants for Akt (e; Akt1 $\left.{ }^{04226}\right)$. $\boldsymbol{h}$, Absolute and relative number of synapses in control flies (D42) or in flies with altered PI3K signaling activity. Numbers inside histograms indicate the sample number per genotype. Asterisks indicate statistically significant differences for all figures. Arrow in $\boldsymbol{g}$ indicates a synaptic bouton with several nc82-positive synapses. Scale bar: $\boldsymbol{a}-\boldsymbol{f}, 20 \mu \mathrm{m} ; \boldsymbol{g}, 8 \mu \mathrm{m}$.
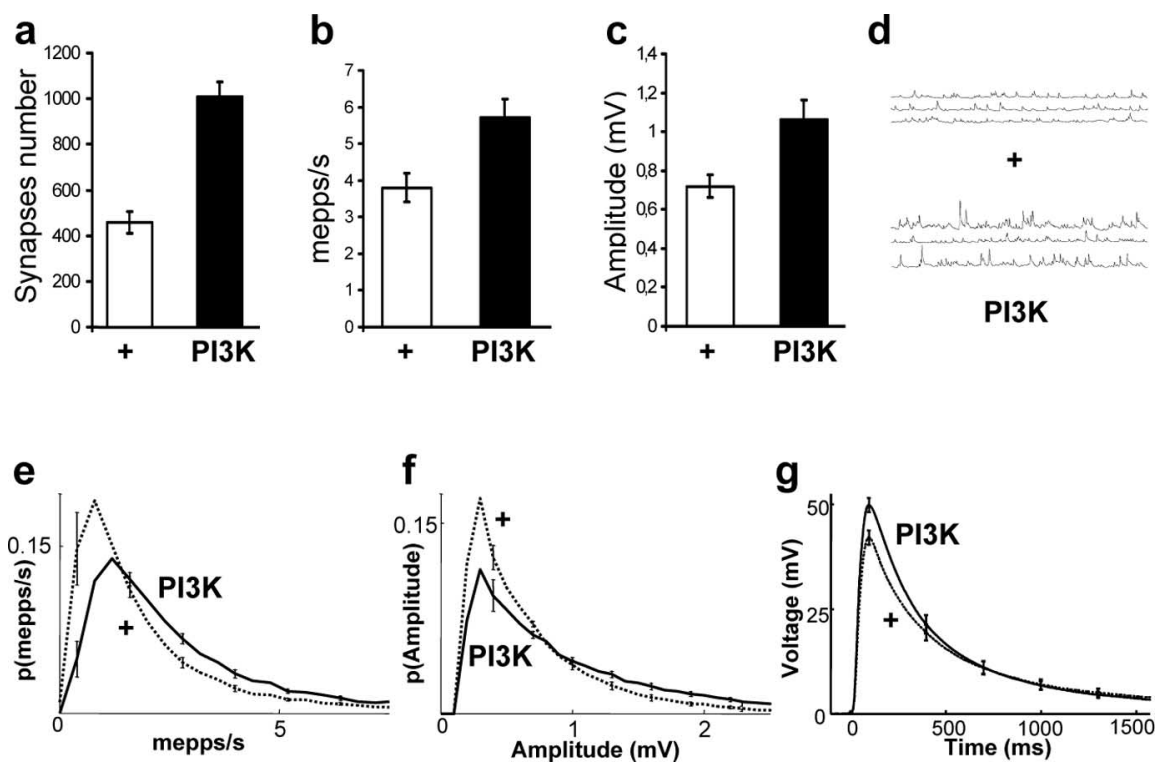

Figure 2. PI3K-induced neuromuscular junction synapses are functional. $\boldsymbol{a}$, Number of synapses, as revealed by nc 82 antibody, in muscle fibers 6 and 7. $\boldsymbol{b}$, Mean frequency of spontaneous mepps at muscle fibers F6 and F7 from late third-instar larvae, indicative of spontaneous neurotransmitter release, is $40 \%$ higher for upregulated PI3K larval fibers (Gal4-D42/UAS-PI3K ${ }^{92 E}$ ) than for control fibers (Gal4-D42) ( $p=0.01 ; n=12)$.c Mean amplitude of the mepps for upregulated PI3K fibers is $40 \%$ higher than for controls $(p<0.01 ; n=12)$. d, Recordings from normal $(+)$ and PI3K overexpressing neuromuscular junctions $6-7 . e_{\text {, }}$ Frequency distribution of mepps for upregulated PI3K fibers is shifted to higher frequencies and broader. $\boldsymbol{f}$, The amplitude distribution of the mepps for upregulated PI3K fibers has the same median as the controls but is broader and with a more important tail at high amplitudes. g, Evoked EPSPs for upregulated PI3K fibers show a significant $9.4 \mathrm{mV}$ increase in amplitude $(p<0.001 ; n=14)$ but the same rise and tail as controls.

have twice as many synapses (nc82-positive puncta) per muscle than controls (Fig. 1a,b,g,h). Conversely, larvae expressing a dominant-negative PI3K carrying a mutated ATP binding site $\left(\mathrm{PI} 3 \mathrm{~K}^{\mathrm{DN}}\right)$ exhibit a reduction in synapse number (Fig. $\left.1 d, h\right)$. To

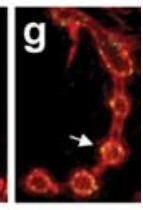

determine whether Akt mediates the synaptogenic activity uncovered by PI3K, we next overexpressed Akt and examined the synapses in the NMJ. We found that Akt upregulation induces a twofold increase in synapse number (Fig. 1c,h). Conversely, reduction of Akt activity decreases synapse number in both heterozygous and homozygous animals (Fig. 1e,h). These observations indicate that PI3K signals through Akt to control synapse number in the larval NMJ.

To analyze whether additional downstream components of the classic InR pathway were required for PI3K synaptogenic activity, we assessed the effects of GSK3 overexpression in larval motor neurons. High levels of GSK3, a negative regulator of Akt signaling, dramatically reduce synapse number in fibers F12 and F13 (Fig. 1f,h), suggesting that GSK3 mediates the synaptogenic activity of PI3K and Akt. Finally, we studied the effects of InR in synapse number in motor neurons. InR overexpression resulted in a moderate, albeit statistically insignificant, increase in synapse number (Fig. $1 h$ ), which could suggest a weak synaptogenic effect consistent with the activity of PI3K and Akt.

\section{PI3K creates functional synapses}

After identifying the supernumerary synapses in motor neurons overexpressing PI3K by the presence of nc82-positive epitopes, we wanted to determine the functionality of these extra synapses. Therefore, we measured the electrophysiological properties of muscle fibers overexpressing PI3K by recording spontaneous and evoked neurotransmitter release from abdominal larval motor neurons. We first confirmed that muscle fibers 6 and 7 expressing PI3K also contain extra synapses as indicated by nc82-positive puncta (Fig. 2a). Spontaneous release from motor neurons overexpressing PI3K, measured as mepps, show a $40 \%$ increase over controls in muscle fibers F6 and F7 (Fig. 2b,d). This is attributable to a median shifted toward a higher frequency than in the controls and to an extended high-frequency tail (Fig. 2e). The mean amplitude of mepps from neurons overexpressing PI3K also reveals a $40 \%$ increase with respect to controls (Fig. 2c). This effect is also detected in the probability distribution (Fig. $2 f$ ), and it likely corresponds to an increase in quantal content. The evoked release, measured as stimulus-induced EPSPs, also produces a $9.4 \mathrm{mV}(22 \%)$ increase in motor neurons overexpressing PI3K (Fig. $2 g$ ). Thus, the observed correlation between synapse number and electrophysiological activity suggests that PI3K induces supernumerary, functional synapses. 


\section{PI3K induces new synapses in projection neurons}

We next assessed the synaptogenic effect of PI3K in projection neurons of the adult brain. For these studies, we selected the Gal4-796 strain, which identifies a defined group of cholinergic neurons (R1-3, $\mathrm{R} 4 \mathrm{~m}$, and $\mathrm{R} 4 \mathrm{~d}$ ) that project to the $\mathrm{EB}$ in the central complex from each side in the adult brain (Fig. 3a,b) (Renn et al., 1999; Strauss, 2002). Gal4-796 is first expressed just before metamorphosis, when the nervous system undergoes major rewiring, and matures during the next $48 \mathrm{~h}$ to form the adult EB (data not shown). Based on serial semithin sections from control adult brains, the EB occupies a total volume of $\sim 83 \times 10^{3} \mu \mathrm{m}^{3}$ (Table 1). Measuring the density of synapses in ultrathin sections, we calculated that the total number of synapses in the EB of a normal 8- to 9-dold female is $\sim 4 \times 10^{6}$ (Table 1). For routine estimates of $\mathrm{EB}$ volumes, however, we quantified synaptic vesicle-tagged GFP signal (syn-GFP) on confocal reconstructions.

We expressed PI3K under the control of Gal4-796 and observed that the EB was 56\% larger (Fig. 3c). The synaptic domain of PI3K-expressing neurons was, however, more than threefold larger, a much larger increase compared with the change in cell size (Fig. $3 c-e, h, i$; Table 1). To better analyze the effects of PI3K on cell size, we visualized single Gal4-796 neurons overexpressing $\mathrm{PI} 3 \mathrm{~K}$ in mosaics. PI3K induces a thicker axon diameter and a wider crown of projections with more abundant synaptic boutons (Fig. 3l,m, arrow). Because this increase in synapse number could be produced by PI3K-stimulated proliferation, we estimated the number of Gal4796 neurons by coexpressing PI3K and nuclear GFP. We found that the number of Gal4-796 neurons is statistically similar in controls ( $36 \pm 4$ neurons; $n=8$ ) and flies overexpressing PI3K $(32 \pm 6$ neurons; $n=6)$. Next, we expressed PI $3 \mathrm{~K}^{\mathrm{DN}}$ in EB neurons to confirm the synaptogenic activity of PI3K in projection neurons. We found that PI3K ${ }^{\mathrm{DN}}$ did not cause the expected reduction of synaptic volume (Fig. $3 c, f, j)$. However, PI $3 \mathrm{~K}^{\mathrm{DN}}$ induced both a reduction in cell size (Fig. $3 c$ ) and an increase in cell number $(44 \pm 3 ; n=8)$. Thus, the supernumerary neurons contributed to an almost normal synaptic domain that compensated for the smaller cell size. This decrease in synapses per neuron is consistent with the previous finding that $\mathrm{PI} 3 \mathrm{~K}^{\mathrm{DN}}$ reduces synapse number in larval motor neurons (Fig. $1 d, h$ ). Additionally, Akt overexpression increases the synaptic domain (Fig. $3 c, g, k$ ), with no significant change in cell number ( $38 \pm 4$ neurons; $n=8$ ). These results indicate that, as described in the larval motor neuron, PI3K signals through Akt to control synapse number in adult brain neurons.
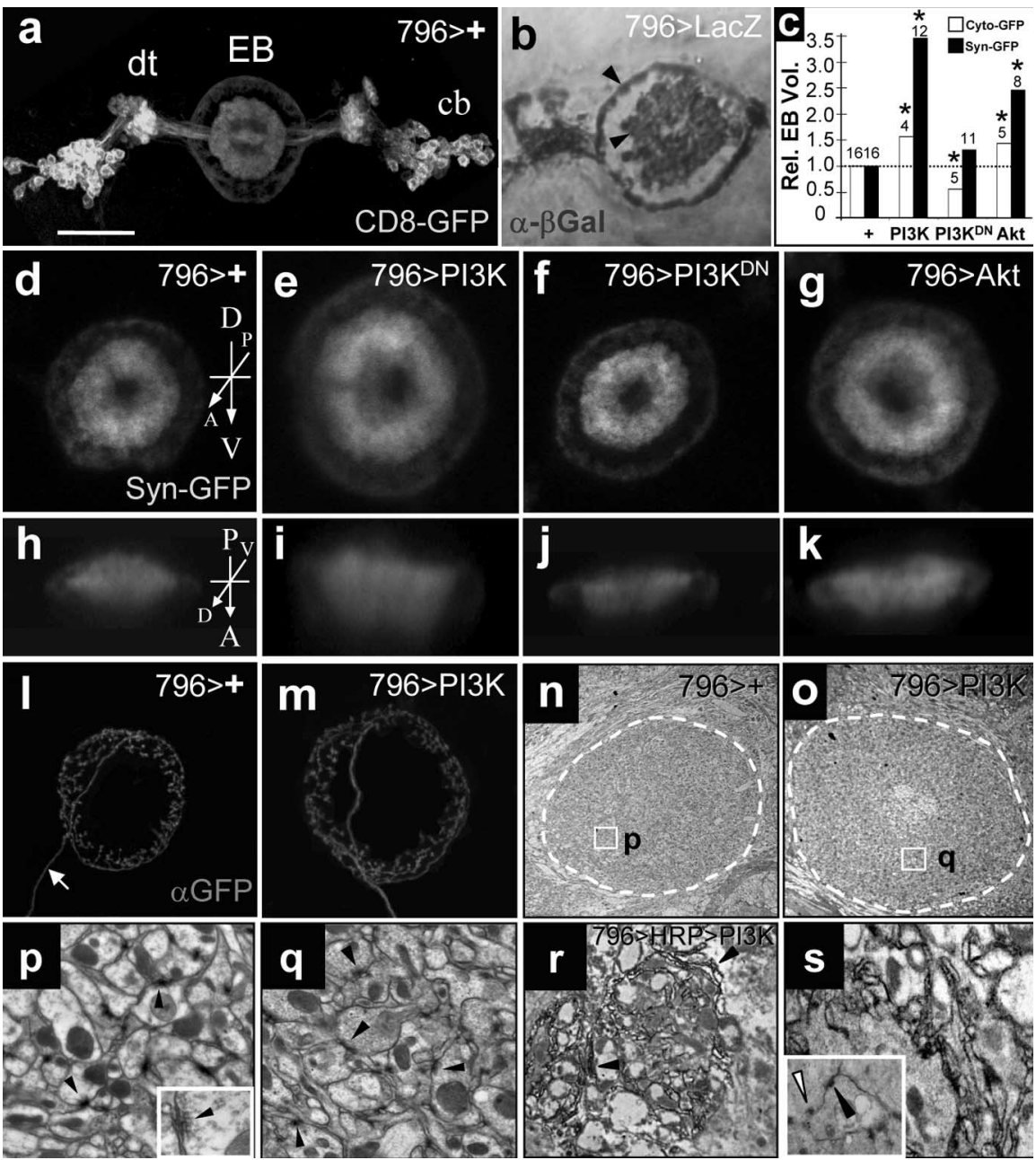

Figure 3. PI3K regulates synapse number in adult central neurons. $\boldsymbol{a}$, Frontal view of a whole-mount adult brain showing 36 neurons [cell bodies (cb)] projecting to the EB from each side and receiving their input through a dendritic tuft (dt) (Gal4 -796/+ UAS-CD8-GFP/+). $\boldsymbol{b}$, Plastic-embedded section of the EB visualized with anti- $\beta$-Gal antibody $(G a l 4-796 /+$; UAS-LacZ/+) shing the glomerular organization of the EB neuropil (arrows). $c$, Effects of PI3K and Akt activity on the relative synaptic volume (syn-GFP) and cell size (cyto-GFP) of EB neurons. Values are normalized with respect to controls $(\mathrm{Gal} 4-796 /+; G F P /+) . \boldsymbol{d}-\boldsymbol{g}$, Confocal serial reconstructions of EBs to measure synaptic volume with syn-GFP (Gal4-796/UAS-syn-GFP) from control (+), whereas $\mathrm{PI} 3 K^{\mathrm{DN}}$ slightly reduces it. $\boldsymbol{h}-\boldsymbol{k}$, Top view of EBs corresponding to previous genotypes. $\boldsymbol{I}, \boldsymbol{m}$, Single R4m neurons expressing CD8 -GFP (Gal4-796/UAS-CD8 -GFP) visualized with anti-GFP from control (+) and UAS-PI3K brains. Cell size changes are (dotted circles) from control (same as $\boldsymbol{d}$ ) and activated PI3K (same as $\boldsymbol{e}$ ) brains. $\boldsymbol{p}, \boldsymbol{q}$, High magnification of insets shown in $\boldsymbol{n}$ and . The arrowheads indicate typical synapse specialization (inset, arrowhead). $r$, s, Dendritic tuft from Gal4-796/+ ; UAS-PI3K shows reciprocal synapses between HRP-positive (black arrowhead) and HRP-negative (white arrowhead) neuronal profiles. Scale bar: $\boldsymbol{a}, \boldsymbol{b}, 40 \mu \mathrm{m} ; \boldsymbol{d}-\boldsymbol{k}, 20 \mu \mathrm{m}$. A, Anterior; $D$, dorsal; P, posterior; V, ventral.

We next visualized and quantified synapses in ultrathin sections of EBs to confirm the indirect estimation of synapse number obtained with the reporter syn-GFP (Fig. $3 n-s)$. Flies overexpressing PI3K displayed 18\% higher density of cell branch profiles compared with controls (Fig. $3 n-q$ ). Most of these profiles showed a higher density of small clear vesicles (Fig. 3p,q), reflecting a $24 \%$ increase in synapse density (Table 1 ). Considering the volume increase, measured in complete sets of serial semithin sections, the estimated total number of synapses in the EB of PI3K animals is $6.4 \times 10^{6}$, or $64 \%$ higher than controls (Table 1 ). Because the EB is composed of a mixture of Gal4-796 neurons and other neurons, only the fraction of neurons expressing PI3K in the EB contribute to the increase in synapse number. There- 


\begin{tabular}{|c|c|c|c|c|c|c|c|c|c|c|}
\hline & \multirow{2}{*}{\multicolumn{4}{|c|}{ Ellipsoid body volume and synapses }} & \multicolumn{6}{|c|}{ Identified ellipsoid body neurons by HRP } \\
\hline & & & & & \multicolumn{2}{|c|}{ Cell profiles/ $\mu \mathrm{m}^{2}$} & \multicolumn{2}{|c|}{ Synapses/ $\mu \mathrm{m}^{2}$} & \multicolumn{2}{|c|}{ Synapses/cell profile } \\
\hline & Volume $\left(\mu \mathrm{m}^{3} \times 10^{3}\right)$ & Synapse density & $n$ & Estimated $N$ & HRP & non-HRP & HRP & non-HRP & HRP & non-HRP \\
\hline Control & $83.2 \pm 2.1$ & $46.9 \pm 2.5$ & 3 & $3.9 \times 10^{6}$ & $2.40 \pm 0.1$ & $2.2 \pm 0.2$ & $1.6 \pm 0.1$ & $1.1 \pm 0.08$ & $0.7 \pm 0.04$ & $0.5 \pm 0.04$ \\
\hline PI3K & $111.2 \pm 7.4$ & $57.9 \pm 2.8$ & 3 & $6.4 \times 10^{6}$ & $4.15 \pm 0.2$ & $2.4 \pm 0.2$ & $3.9 \pm 0.3$ & $0.8 \pm 0.15$ & $0.9 \pm 0.04$ & $0.4 \pm 0.03$ \\
\hline Difference & $\Delta 1.3^{*}$ & $\Delta 1.2$ & & $\Delta N=1.64^{*}$ & $\Delta 1.73^{*}$ & $\Delta 1.09$ & $\Delta 2.43^{*}$ & $\Delta 0.72$ & $\Delta 1.4^{*}$ & $\Delta 0.8$ \\
\hline
\end{tabular}

*Significant difference of $p<0.05$ or better.
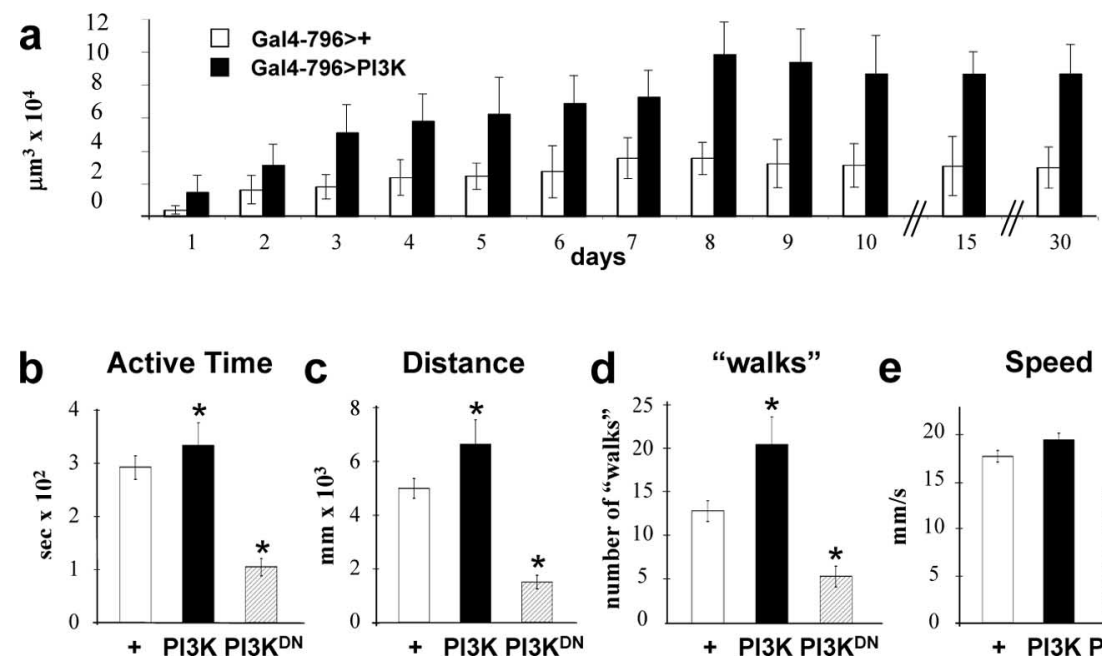

Figure 4. Characterization of the PI3K synaptogenic effect. $\boldsymbol{a}$, The developmental profile of EB synaptic volume (Gal4-796/ UAS-syn-GFP) is similar in control (+) and PI3K-overexpressing (UAS-PI3K) flies. The EB size difference is detected at all ages. $\boldsymbol{b}-\boldsymbol{d}$, The locomotion assay in the Buridan's arena shows increased active time $(\boldsymbol{b})$, walked distance $(\boldsymbol{c})$, and the number of full walks between landmarks in adult flies expressing PI3K compared with controls (genotypes as in $\boldsymbol{a}$ ). The expression of PI3K ${ }^{\mathrm{DN}}$ yields opposite effects. Movement speed $(\boldsymbol{e})$ remains normal in $\mathrm{PI} 3 \mathrm{~K}$ but reduced in $\mathrm{PI} 3 \mathrm{~K}^{\mathrm{DN}}$ animals.

fore, the synaptogenic activity of PI3K in the EB projection neurons may be underestimated. To more precisely assess the synaptogenic effect of PI3K, we coexpressed PI3K and HRP and found that neurons overexpressing $\mathrm{PI} 3 \mathrm{~K}\left(\mathrm{HRP}^{+}\right)$contain 2.4-fold more synapses than non-HRP neurons (Fig. 3r,s; Table 1). These data demonstrate that PI3K upregulation leads to a drastic, cellautonomous increase in synapse number.

After demonstrating the synaptogenic activity of PI3K, we wanted to assess the effect of PI3K in the pattern of synapse accumulation during aging. In control flies, the EB volume visualized by syn-GFP grows for several days and reaches its maximum by $8-9 \mathrm{~d}$ after eclosion. This is followed by a slight decline in EB volume and a period of steady EB volume for most of adult life (Fig. 4a). This temporal profile of progressive synaptic accumulation is also found in the antennal lobe (Devaud et al., 2003), the larval third-instar NMJ (Rivlin et al., 2004), and the optic ganglia (Barth et al., 1997). Thus, several neuronal types and brain nuclei seem to be subjected to a similar synaptic maturation process. Flies overexpressing PI3K show a normal maturation profile, albeit with values consistently higher than the sibling controls (Fig. 4a). Therefore, the synaptogenic effect of PI3K is maintained throughout the lifespan of the animal without signs of instability or compensatory reductions later in life.

\section{PI3K overexpression induces behavioral changes}

We learned above that the PI3K-induced ectopic synapses cause electrophysiological changes in motor neuron. Next we asked whether these synapses in the EB can modify behavior. Because the EB is known to control movements in the adult fly (Strauss,

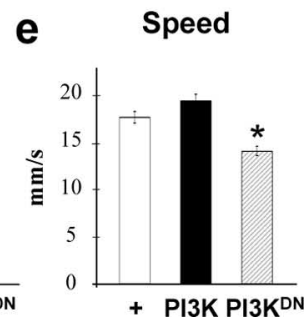

2002), we assayed the functional effect of the PI3K-induced synapses in the Buridan's arena. This is a locomotion test based on the optomotor response to two opposing black bars on a homogeneously illuminated background. Animals overexpressing $\mathrm{PI} 3 \mathrm{~K}$ in EB neurons are active for longer periods and, consequently, walk longer distances than their sibling controls (Fig. $4 b, c$ ). Also, the number of full walks between the black bars was higher in PI3K animals (Fig. $4 d$ ). The speed of movement remained unaffected (Fig. 4e). To assay whether these effects were specific to PI3K rather than to overall disruption of behavior, we overexpressed PI $3 \mathrm{~K}^{\mathrm{DN}}$. The data show opposite locomotion effects (Fig. $4 b-e)$. In addition, we also tested locomotor activity in larvae expressing $\mathrm{PI} 3 \mathrm{~K}$ in motor neurons (Gal4-D42/UAS-PI3K) and found that they crawled distances twice as long as their controls (Gal4D42/+) (data not shown). Together, we conclude that PI3K upregulation induces the formation of functionally active ectopic synapses that can elicit changes in locomotor behavior.

\section{Synaptogenic activity of PI3K signaling components}

We proceeded to analyze other components of the PI3K signaling to investigate which factors mediate PI3K synaptogenic activity in brain neurons. Overexpression of the Akt substrate Rheb induces a significant increase of the synaptic domain (Fig. 5a), although weaker than PI3K and Akt (Fig. 3c). Another repressor of PI3K signaling, GSK3, showed a clear ability to modulate synapse number in the larval NMJ (Fig. 1f). GSK3 overexpression significantly reduced the synaptic domain in the EB (Fig. 5a). Thus, consistent with the results in the larval motor neurons, GSK3 upregulation exhibits anti-synaptogenic activity in projection neurons. This observation complements and is consistent with a previous report showing that the downregulation of GSK3 increases synapse number (Franco et al., 2004).

We also assessed the synaptogenic activity of InR in projection neurons to analyze the upstream regulators of PI3K. As in the larval motor neurons, we observed a correlation between InR activity and synapse number in the EB (Fig. 5b). However, because the InR controls cell proliferation (Fingar et al., 2004), we explored the possibility that the changes in synapse number could be an indirect consequence of changes in the number of Gal4796 neurons. Indeed, InR overexpression induced supernumerary EB neurons ( $46 \pm 1 ; n=6$ ), whereas its downregulation showed no significant effect $(39 \pm 5 ; n=4)$. Thus, the increase in synapses is likely to result from these additional neurons. To further confirm this result, we assayed the synaptogenic effect of 
Chico, the fly ortholog of the mammalian insulin receptor substrate. We found that, in chico mutant brains, the synaptic volume in the EB is severely reduced (Fig. 5b). However, the $30 \%$ reduction in the number of Gal4-796 neurons in chico mutants (23 $\pm 1 ; n=8)$ does not fully account for the $80 \%$ reduction in synaptic volume. These observations confirm the involvement of InR and Chico in synaptogenesis, although these two signaling components display complex phenotypes because of their role in cell proliferation.

\section{Synapse number is not directly} controlled by cell size

By modulating PI3K activity, we observed a correlation between cell size and synapse number, thus suggesting that synapses are directly regulated by cell size. To test this hypothesis, we measured the synaptogenic activity of other signaling molecules known to regulate cell size. The EgfR signal is necessary for cell proliferation and cell viability and controls cell size in Drosophila (Diaz-Benjumea and Hafen, 1994). We confirmed here that both upregulation and downregulation of EgfR alter the size of Gal4796 neurons (Fig. 5c). EB neurons expressing EgfR or EgfR ${ }^{\mathrm{DN}}$, however, showed no significant change in synapse number, indicating that changes in cell size do not directly control synapse number. Therefore, PI3K could be involved in different pathways to independently control cell size and synaptogenesis.

\section{Neo-synapses require continuous PI3K activity}

We next asked whether persistent PI3K activity was necessary in aged adults to maintain the neo-synapses formed during neural differentiation. The temporal control of PI3K expression was achieved using the TARGET regulatory system based in Gal $80^{\text {ts }}$ (McGuire et al., 2003). We designed a "switch-off" protocol in which flies coexpressed PI3K and syn-GFP or only syn-GFP in EB neurons until day 8 after eclosion to allow full synaptic maturation (Fig. 6a). At this time, when PI3K had induced a threefold increase in synaptic volume, Gal4 activity was switched off by transferring the flies to the permissive temperature $\left(17^{\circ} \mathrm{C}\right)$ for Gal80 ${ }^{\text {ts }}$ repressor activity. The flies were subsequently maintained for 2 more days for measurements of synaptic volume in the EB at days 9 and 10. Reversion to endogenous PI3K activity causes a rapid elimination of synapses (Fig. $6 a$ ). At $48 \mathrm{~h}$ after the switch-off, the amount of syn-GFP signal is comparable in PI3K and control flies. The same effect is observed when the switch-off is performed at a more advanced age (Fig. 6b). Because syn-GFP expression is also dependent on Gal4 activity, syn-GFP signal drops $50 \%$ in control flies. However, in PI3K flies, syn-GFP signal drops by $80 \%$ in $48 \mathrm{~h}$. Thus, the syn-GFP signal is lost much faster in PI3K flies than control flies. These results suggest that high levels of PI3K activity are necessary not only for the formation of ectopic synapses but also for subsequent synapse maintenance. These data also show an unexpected degree of synapse dynamics in mature, fully differentiated brain neurons, with a synaptic halflife of $\sim 24 \mathrm{~h}$.

\section{PI3K can induce synapses in adult neurons}

Next, we asked whether PI3K has the ability to induce neosynapses in aged adult flies. For this, we designed a "switch-on" protocol in which PI3K was not expressed during developmental stages or in young adults but was later turned on in EB neurons of older adult flies (Fig. 7). In switch-on experiments, adult flies were raised at the permissive temperature (Gal80 active) and were later placed at the restrictive temperature (Gal80 inactive) at days 15,30 , or 50 . Because Gal4 controls both PI3K and the reporter syn-GFP, at least $15 \mathrm{~d}$ are needed after the switch-on for proper reporter detection. The reporter signal was, therefore, visualized at days 40,45 , or 65 , respectively. We found that turning on PI3K expression in 15-, 30-, or 50-d-old adult flies induces an increase in syn-GFP signal. Regardless of the time of PI3K induction, these flies achieve a twofold increase of synaptic domain (Fig. 7a,b). This synaptogenic effect is weaker than the threefold effect described in constitutive PI3K overexpression experiments. This observation suggests that mature neurons have lost some of the plasticity shown by developing neurons. The increase in synapse number was subsequently confirmed by the accumulation of nc82 epitopes (Fig. $7 c, d$ ), indicating that the PI3K synaptogenic effects can be detected also by endogenous synaptic markers. The general brain ultrastructure of a 50-d-old fly shows the characteristic vacuolar appearance and electron-dense body inclusions of aged neurons (Fig. $7 e, f, g$ ). However, in the EB neuropil, in which the terminals of the PI3K-expressing neurons are located, the cell profiles and the synapses are well preserved (Fig. 7h).

Additionally, we examined the dendritic tuft in single R4d neuron mosaics to detect dendritogenic effects akin to those described on synapses. High-resolution confocal images indicate that constitutive PI3K overexpression increases dendritic tuft branching compared with controls (data not shown). Moreover, PI3K switch-on in 30-d-old flies also increases dendritic branching in 52-d-old flies. These observations demonstrate that synapses and dendrites can be modified in fully differentiated, mature neurons in aged flies. Synaptogenesis and dendritogenesis are thus controlled through a cell-autonomous, PI3K-dependent mechanism.

\section{Conservation of PI3K synaptogenic activity in human neurons}

To determine whether the synaptogenic activity of PI3K is conserved in human cells, we modulated PI3K activity on SH-SY5Y human neuroblastoma cells. We first stimulated PI3K activity by treating SH-SY5Y cells with 740Y-P, a pharmacological activator of $\mathrm{PI} 3 \mathrm{~K}$ that mimics phosphorylated TKR residue binding to the p85 regulatory subunit (Derossi et al., 1998). Then, we monitored the cellular localization and expression level of SV2, a synaptic vesicle protein (Schivell et al., 2005). 740Y-P induced the translocation of SV2 from a perisomatic compartment to the emerging neurite-like cellular processes (Fig. $8 a, b$ ). This change in subcellular localization was accompanied by a $20 \%$ increase in SV2 

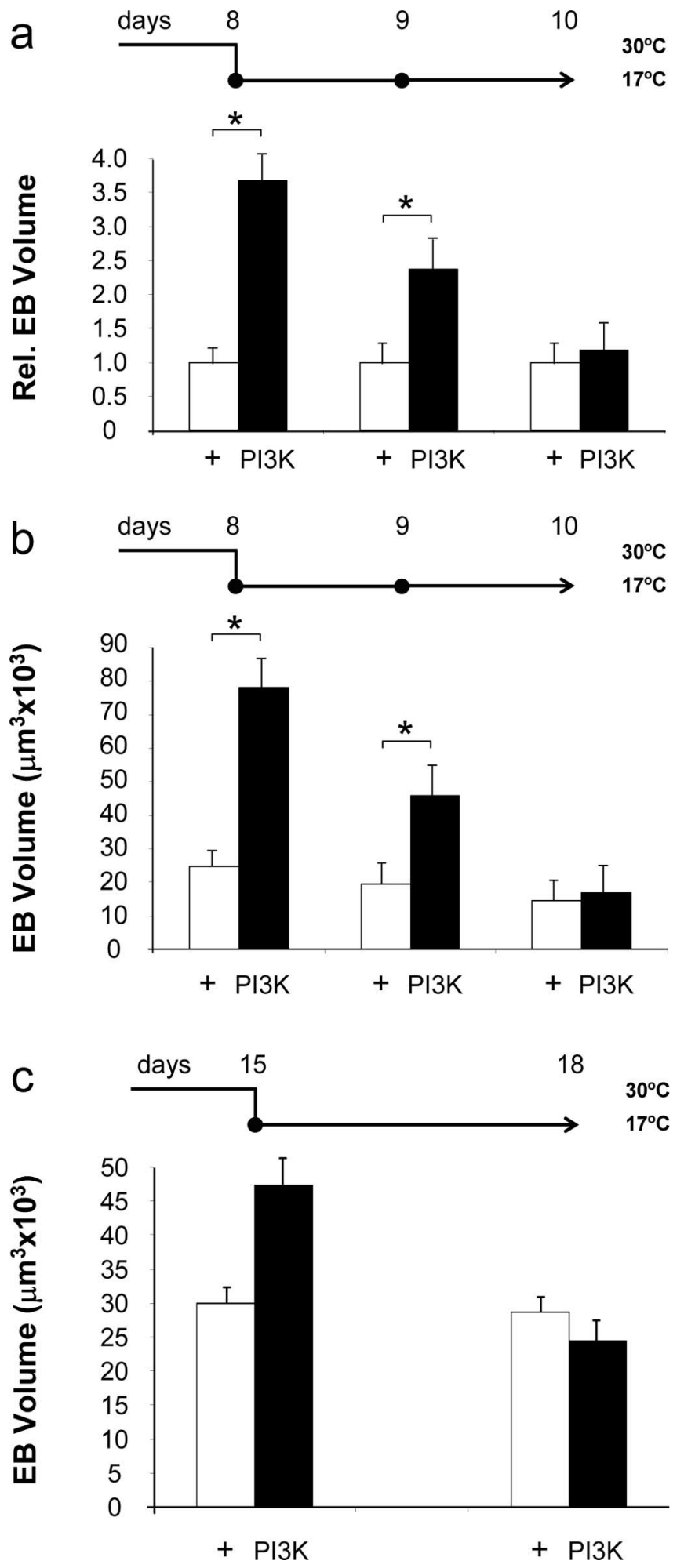

Figure 6. PI3K activity is necessary for synapse maintenance. $\boldsymbol{a}, \boldsymbol{b}$, Relative $(\boldsymbol{a})$ and absolute (b) synaptic volume of the EB (Gal4-796/UAS-syn-GFP; Gal80 ts/+) in control (+) or PI3Kexpressing (UAS-PI3K) flies in which Gal4 activity was switched off in 8-d-old adult flies. Flies were raised at $30^{\circ} \mathrm{C}$ until adults reached $8 \mathrm{~d}$. This temperature inhibits $\mathrm{Gal} 80^{\text {ts }}$, allowing Gal4 activity. Then, the culture temperature was shifted to $17^{\circ} \mathrm{C}$, allowing Gal $80^{\text {ts }}$ to repress $\mathrm{Gal} 4$ activity (switch-off). Syn-GFP was measured on days 8, 9, and 10. c, Equivalent experiments switching off the Gal4-796 expression at day 15 and measuring at day 18 . The synaptic volume decreases dramatically in PI3K flies, indicating that the ectopic synapses require constant PI3K stimulation.
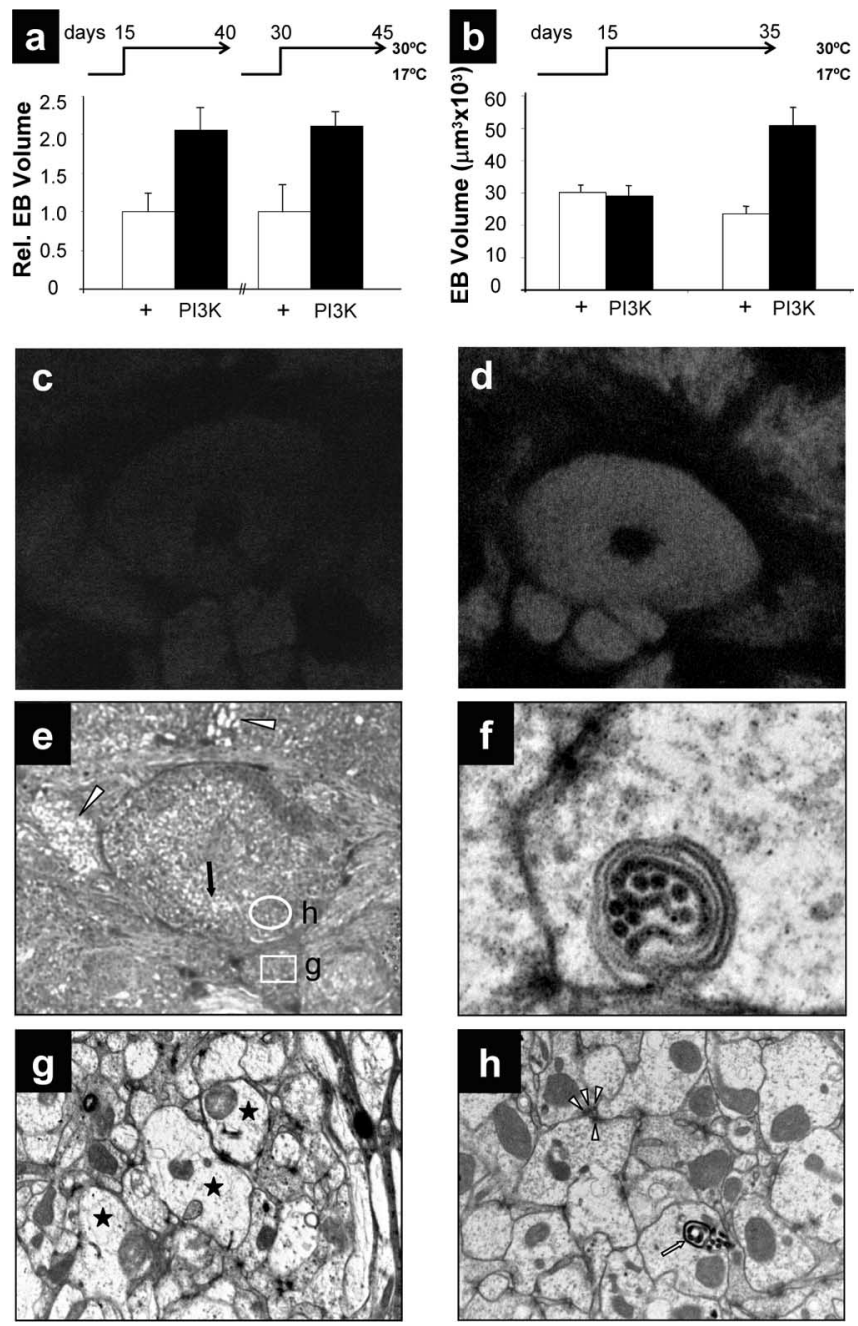

Figure 7. PI3K is sufficient for synapse formation and it protects aging neurons. $\boldsymbol{a}$, Relative synaptic volume of the EB (Gal4-796/UAS-syn-GFP; Gal80 $5 /+$ ) in control (+) or PI3Kexpressing (UAS-PI3K) flies in which Gal4 activity was switched on in 15- or 30-d-old adult flies. Flies were raised at $17^{\circ} \mathrm{C}$ until adults reached 15 or $30 \mathrm{~d}$ (top). This temperature allows $\mathrm{Gal} 80^{\text {ts }}$ to repress Gal 4 activity (no expression). Then, the culture temperature was shifted to $30^{\circ} \mathrm{C}$, inhibiting Gal80 ts and allowing Gal4 activity (switch-on). syn-GFP was measured at least $15 \mathrm{~d}$ later. Flies that start expressing PI3K at days 15 (left) or 30 (right) induce significant number of neo-synapses when analyzed at days 40 and 45 , respectively. $\boldsymbol{b}$, Absolute volume of the EB from brains subjected to switch-on experiments but monitoring synapses by the nc 82 antibody. $\boldsymbol{c}, \boldsymbol{d}$, Frontal views of EBs seen as stacks of confocal planes from an experiment as in $\boldsymbol{b}$ visualized at day 35. Note the higher synaptic signal in the PI3K brain (d) with respect to control (c). e, Toluidine blue-stained semithin section of the EB of a 50-d-old adult subjected to PI3K switch-on at day 30. Age-related vacuoles are abundant in areas adjacent to the EB (arrowheads) and in a crown within the EB (black arrow). $f$, Anomalous electron-dense bodies characteristic of aged neurons. $\boldsymbol{g}$, High-magnification TEM corresponding to the square in e showing age-characteristic disorganization of the cytoskeleton (stars) and the general depletion of electron-dense materials. $\boldsymbol{h}$, High-magnification TEM of the circle in $\boldsymbol{e}$ showing abundance of small synaptic vesicles and multiple synapses converging on a single dendrite (arrowheads). Age-related electron-dense bodies (arrow) can also be found in some neurons.

signal (Fig. 8c,d). As expected, 740Y-P increases the amount of phosphorylated Akt (Fig. 8c,d), indicating an efficient PI3K activation. Conversely, the PI3K inhibitors LY294002 (Fig. 8c,d) or wortmannin (data not shown) induced $70 \%$ reduction in SV2 levels together with a $30 \%$ reduction in the level of phosphorylated Akt. These data indicate that the synaptogenic activity of PI3K/Akt described in flies is likely to be conserved in human neurons. 

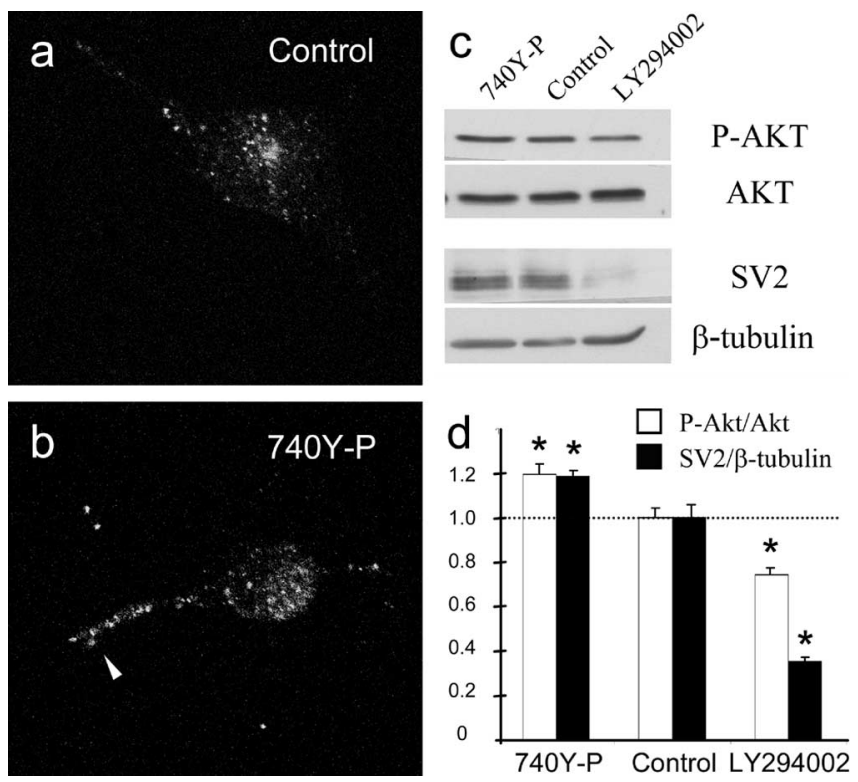

Figure 8. PI3K regulates expression and localization of synaptic markers in human neuroblastoma cells. $\boldsymbol{a}$, Distribution of the synaptic vesicle marker SV2 (green) in normal SH-SY5Y cultured cells. $\boldsymbol{b}$, SH-SY5Y cells incubated with $50 \mu \mathrm{g} / \mathrm{ml} 740$ Y-P induce the translocation of SV2 to the projections. $\boldsymbol{c}, \boldsymbol{d}, 740 \mathrm{Y}-\mathrm{P}$ induces higher expression levels of SV2 and higher levels of phospho-Akt as detected in Western blot. LY294002 (5 $\mu \mathrm{m})$ and wortmannin (10 $\mu \mathrm{m})$ reduce SV2 levels by $70 \%$ and phosphorylated Akt by $30 \%$. Phospho-Akt levels are measured with respect to total Akt, and SV2 levels are normalized versus $\beta$-tubulin. White histograms, Control culture; black histograms, treated culture.

\section{Discussion}

In an effort to determine how cell size controls synapse number, we found that PI3K signaling exerts a potent synaptogenic effect in both Drosophila neurons and human neuroblastoma cells. Our data demonstrate that PI3K upregulation induces supernumerary synapses in larval motor neurons and in projection neurons of the adult brain. These supernumerary synapses are functional, as indicated by the electrophysiological and behavioral alterations described in flies overexpressing PI3K or PI3K ${ }^{\mathrm{DN}}$. Remarkably, PI3K can modulate synapse number during neuronal development, in young adult flies and even in aged flies. Also, continuous PI3K activity is necessary to maintain the supernumerary synapses, suggesting that PI3K activity levels tightly regulate synaptogenesis. Moreover, modulation of other signaling pathways that regulate cell size and survival, such as EgfR, do not affect synapse number. Overall, these results indicate that synapse number is not directly regulated by cell size but rather by an independent synaptogenic activity of PI3K.

The involvement of PI3K in growth cone dynamics (Laurino et al., 2005), neurite growth (Sanchez et al., 2001), and synapse function (Ramsey et al., 2005) is well documented. Some of these effects include the formation of complexes between PI3K and synapsin (Cousin et al., 2003) or actin filaments (Ramsey et al., 2005) as well as increased levels of phosphoinositides. The latter, in turn, are linked to the cAMP pathway (Brailoiu et al., 2003) and thus to CAMP response element-binding protein-dependent changes in gene expression. The present morphological evidence for PI3K-dependent synapse formation in Drosophila has a functional precedent in a crayfish study in which PI3K activity and local translation of calcineurin mRNA were required for the formation of novel active zones at the neuromuscular junction (Beaumont et al., 2001). However, the effectors of this synaptogenic activity of PI3K still need to be identified.
The synaptogenic activity of PI3K also requires Akt and Rheb, two signaling components of the InR pathway. Previous reports show that insulin plays a role in neural connectivity during development (Song et al., 2003), synapse activity (Huang et al., 2003), and adult behavior (Zhao et al., 1999). Moreover, the InR is a structural constituent of synapses (Abbott et al., 1999). In mice, insulin-like growth factor I (IGF-I) deficit impairs differentiation of neural stem cells (Vicario-Abejon et al., 2003). Conversely, IGF-I overexpression during postnatal day 7 (P7) to P21 increases neuropil volume and synapse number, although supernumerary synapses are lost by P130 (O’Kusky et al., 2003). In hippocampal CA1 neurons, insulin stimulates the translation (but not the transcription) of postsynaptic density PSD-95 through a PI3K-Akt-mTOR (mammalian target of rapamycin) pathway (Lee et al., 2005). Indeed, our data reveal a selective effect of PI3K on synaptogenesis, which is InR independent, and agree with those from neuron-specific InR knock-out mice in which behavioral alterations could not be detected despite the lack of insulin-mediated PI3K activation (Schubert et al., 2004). Thus, it seems that the PI3K synaptogenic mechanism pointed out here partially overlaps with the canonical InR pathway activated in response to insulin. In this regard, it is relevant to note that insulin signals through different pathways to control apoptosis versus DNA synthesis in Drosophila (Bikopoulos et al., 2004). Most likely, insulin and its canonical signaling pathway will modulate synapse function through stimulation of local translation of selected mRNAs in an activity-dependent process (Schratt et al., 2004). In contrast, the formation of new synapses would require a distinct mechanism or different targets. In fact, the insulin-induced functional changes in the synapse are selective for AMPA versus NMDA neurotransmitter receptors (Huang et al., 2004), demonstrating that the insulin effect cannot be described as synaptogenic for all neurons.

The actual pathway sustaining PI3K synaptogenesis, although incomplete at this time, must be coordinated with other synaptogenic mechanisms described previously. For instance, the $\mathrm{Wg}$ (wingless)/Wnt (wingless-type MMTV integration site family) and TGF $\beta$ signaling pathways coordinate the localization of presynaptic and postsynaptic elements acting as secreted morphogens (Packard et al., 2002), and GSK3, PI3K, and Akt mediate specific steps of this signaling. Also, the focal adhesion kinase (Arendt et al., 2004; Rico et al., 2004; Ruiz-Canada et al., 2004), atypical protein kinase C (Ruiz-Canada et al., 2004), or the protooncogene ras (Arendt et al., 2004) are known to play a role in synaptogenesis, although their corresponding pathways remain unknown.

The anti-synaptogenic effect of GSK3 overexpression shown here, in conjunction with the synaptogenic activity caused by its downregulation (Franco et al., 2004), can be explained by the functional relevance of some of GSK3 targets. GSK3 phosphorylates the cytoskeletal Tau protein (Agarwal-Mawal et al., 2003) and the membrane-bound $\beta$-catenin (Espada et al., 2005). Elevated GSK3 activity would lead to reduced $\beta$-catenin mediated cell-to-cell interactions, along with increased cytoskeletal rigor attributable to Tau-mediated microtubule hyperstability (Cho and Johnson, 2004). In addition, GSK3 association with the TSC1/TSC2 complex may synergize $\beta$-catenin degradation, which, in turn, abolishes Wnt signaling (Mak et al., 2005). The GSK3 effect on microtubule dynamics seems to be PI3K independent, as shown in NGF-stimulated PC12 cells (Goold and Gordon-Weeks, 2001). This could explain the differential effect on cell size versus synaptogenesis observed here for GSK3 upregulation. We propose that at least the signaling elements de- 
scribed here cooperate in an intricate regulatory network controlling metabolic activity, cell size, and synaptogenesis.

The conditional upregulation of PI3K signaling shown here indicates that sprouting can be re-elicited in aged flies, demonstrating that neuronal rejuvenation is feasible in fully mature or aged adult brains. In the same context, the neuroprotective effects described here for the PI3K upregulation have a precedent in ischemic rodent hippocampi after sodium orthovanadate treatment that upregulates Akt activity (Fukunaga et al., 2005). Considering the conservative nature of signaling pathways and the experiments on human neuroblastoma cells, it is likely that the synaptogenic effect of PI3K described in Drosophila could also be effective in humans. These findings could prompt the development of a number of clinical applications, including delaying aging or reversing the cognitive deficits characteristic of many neurological disorders.

\section{References}

Abbott MA, Wells DG, Fallon JR (1999) The insulin receptor tyrosine kinase substrate p58/53 and the insulin receptor are components of CNS synapses. J Neurosci 19:7300-7308.

Acebes A, Ferrus A (2001) Increasing the number of synapses modifies olfactory perception in Drosophila. J Neurosci 21:6264-6273.

Agarwal-Mawal A, Qureshi HY, Cafferty PW, Yuan Z, Han D, Lin R, Paudel HK (2003) 14-3-3 connects glycogen synthase kinase-3 beta to tau within a brain microtubule-associated tau phosphorylation complex. J Biol Chem 278:12722-12728.

Arendt T, Gartner U, Seeger G, Barmashenko G, Palm K, Mittmann T, Yan L, Hummeke M, Behrbohm J, Bruckner MK, Holzer M, Wahle P, Heumann R (2004) Neuronal activation of Ras regulates synaptic connectivity. Eur J Neurosci 19:2953-2966.

Barth M, Hirsch HV, Meinertzhagen IA, Heisenberg M (1997) Experiencedependent developmental plasticity in the optic lobe of Drosophila melanogaster. J Neurosci 17:1493-1504.

Beaumont V, Zhong N, Fletcher R, Froemke RC, Zucker RS (2001) Phosphorylation and local presynaptic protein synthesis in calcium- and calcineurin-dependent induction of crayfish long-term facilitation. Neuron 32:489-501.

Bikopoulos G, Ceddia RB, Sweeney G, Hilliker AJ (2004) Insulin reduces apoptosis and increases DNA synthesis and cell size via distinct signalling pathways in Drosophila Kc cells. Cell Prolif 37:307-316.

Bourouis M (2002) Targeted increase in shaggy activity levels blocks wingless signaling. Genesis 34:99-102.

Brailoiu E, Miyamoto MD, Dun NJ (2003) Inositol derivatives modulate spontaneous transmitter release at the frog neuromuscular junction. Neuropharmacology 45:691-701.

Canal I, Farinas CI, Gho M, Ferrus A (1994) The presynaptic cell determines the number of synapses in the Drosophila optic ganglia. Eur J Neurosci 6:1423-1431.

Cantley LC (2002) The phosphoinositide 3-kinase pathway. Science 296:1655-1657.

Cho JH, Johnson GV (2004) Glycogen synthase kinase 3 beta induces caspase-cleaved tau aggregation in situ. J Biol Chem 279:54716-54723.

Coggan JS, Grutzendler J, Bishop DL, Cook MR, Gan W, Heym J, Lichtman JW (2004) Age-associated synapse elimination in mouse parasympathetic ganglia. J Neurobiol 60:214-226.

Cousin MA, Malladi CS, Tan TC, Raymond CR, Smillie KJ, Robinson PJ (2003) Synapsin I-associated phosphatidylinositol 3-kinase mediates synaptic vesicle delivery to the readily releasable pool. J Biol Chem 278:29065-29071.

Derossi D, Williams EJ, Green PJ, Dunican DJ, Doherty P (1998) Stimulation of mitogenesis by a cell-permeable PI 3-kinase binding peptide. Biochem Biophys Res Commun 251:148-152.

Devaud JM, Ferrus A (2003) Molecular genetics of activity-dependent structural changes at the synapse. J Neurogenet 17:271-293.

Devaud JM, Acebes A, Ramaswami M, Ferrus A (2003) Structural and functional changes in the olfactory pathway of adult Drosophila take place at a critical age. J Neurobiol 56:13-23.

Diaz-Benjumea FJ, Hafen E (1994) The sevenless signalling cassette medi- ates Drosophila EGF receptor function during epidermal development. Development 120:569-578.

Espada J, Peinado H, Esteller M, Cano A (2005) Direct metabolic regulation of beta-catenin activity by the p85alpha regulatory subunit of phosphoinositide 3-OH kinase. Exp Cell Res 305:409-417.

Estes PS, Ho GL, Narayanan R, Ramaswami M (2000) Synaptic localization and restricted diffusion of a Drosophila neuronal synaptobrevin-green fluorescent protein chimera in vivo. J Neurogenet 13:233-255.

Fingar DC, Richardson CJ, Tee AR, Cheatham L, Tsou C, Blenis J (2004) mTOR controls cell cycle progression through its cell growth effectors S6K1 and 4E-BP1/eukaryotic translation initiation factor 4E. Mol Cell Biol 24:200-216.

Franco B, Bogdanik L, Bobinnec Y, Debec A, Bockaert J, Parmentier ML, Grau Y (2004) Shaggy, the homolog of glycogen synthase kinase 3, controls neuromuscular junction growth in Drosophila. J Neurosci 24:6573-6577.

Freeman M (1996) Reiterative use of the EGF receptor triggers differentiation of all cell types in the Drosophila eye. Cell 87:651-660.

Fukunaga K, Ishigami T, Kawano T (2005) Transcriptional regulation of neuronal genes and its effect on neural functions: expression and function of forkhead transcription factors in neurons. J Pharmacol Sci 98:205-211.

Gan WB, Kwon E, Feng G, Sanes JR, Lichtman JW (2003) Synaptic dynamism measured over minutes to months: age-dependent decline in an autonomic ganglion. Nat Neurosci 6:956-960.

Geinisman Y, Ganeshina O, Yoshida R, Berry RW, Disterhoft JF, Gallagher M (2004) Aging, spatial learning, and total synapse number in the rat CA1 stratum radiatum. Neurobiol Aging 25:407-416.

Goold RG, Gordon-Weeks PR (2001) Microtubule-associated protein 1B phosphorylation by glycogen synthase kinase 3beta is induced during PC12 cell differentiation. J Cell Sci 114:4273-4284.

Gulyas AI, Megias M, Emri Z, Freund TF (1999) Total number and ratio of excitatory and inhibitory synapses converging onto single interneurons of different types in the CAl area of the rat hippocampus. J Neurosci 19:10082-10097.

Harris KM, Fiala JC, Ostroff L (2003) Structural changes at dendritic spine synapses during long-term potentiation. Philos Trans R Soc Lond B Biol Sci 358:745-748.

Honer WG (2003) Pathology of presynaptic proteins in Alzheimer's disease: more than simple loss of terminals. Neurobiol Aging 24:1047-1062.

Huang CC, You JL, Lee CC, Hsu KS (2003) Insulin induces a novel form of postsynaptic mossy fiber long-term depression in the hippocampus. Mol Cell Neurosci 24:831-841.

Huang CC, Lee CC, Hsu KS (2004) An investigation into signal transduction mechanisms involved in insulin-induced long-term depression in the CA1 region of the hippocampus. J Neurochem 89:217-231.

Inoki K, Zhu T, Guan KL (2003) TSC2 mediates cellular energy response to control cell growth and survival. Cell 115:577-590.

Juusola M, de Polavieja GG (2003) The rate of information transfer of naturalistic stimulation by graded potentials. J Gen Physiol 122:191-206.

Kolomeets NS, Orlovskaya DD, Rachmanova VI, Uranova NA (2005) Ultrastructural alterations in hippocampal mossy fiber synapses in schizophrenia: a postmortem morphometric study. Synapse 57:47-55.

Kretz O, Fester L, Wehrenberg U, Zhou L, Brauckmann S, Zhao S, PrangeKiel J, Naumann T, Jarry H, Frotscher M, Rune GM (2004) Hippocampal synapses depend on hippocampal estrogen synthesis. J Neurosci 24:5913-5921.

Laurino L, Wang XX, de la Houssaye BA, Sosa L, Dupraz S, Caceres A, Pfenninger KH, Quiroga S (2005) PI3K activation by IGF-1 is essential for the regulation of membrane expansion at the nerve growth cone. J Cell Sci 118:3653-3662.

Lee CC, Huang CC, Wu MY, Hsu KS (2005) Insulin stimulates postsynaptic density-95 protein translation via the phosphoinositide 3-kinase-Aktmammalian target of rapamycin signaling pathway. J Biol Chem 280:18543-18550.

Lee T, Luo L (2001) Mosaic analysis with a repressible cell marker (MARCM) for Drosophila neural development. Trends Neurosci 24:251-254.

Leevers SJ, Weinkove D, MacDougall LK, Hafen E, Waterfield MD (1996) The Drosophila phosphoinositide 3-kinase Dp110 promotes cell growth. EMBO J 15:6584-6594.

Luebke JI, Chang YM, Moore TL, Rosene DL (2004) Normal aging results in decreased synaptic excitation and increased synaptic inhibition of layer 
$2 / 3$ pyramidal cells in the monkey prefrontal cortex. Neuroscience 125:277-288.

Madziar B, Lopez-Coviella I, Zemelko V, Berse B (2005) Regulation of cholinergic gene expression by nerve growth factor depends on the phosphatidylinositol-3'-kinase pathway. J Neurochem 92:767-779.

Mak BC, Kenerson HL, Aicher LD, Barnes EA, Yeung RS (2005) Aberrant beta-catenin signaling in tuberous sclerosis. Am J Pathol 167:107-116.

Marygold SJ, Leevers SJ (2002) Growth signaling: TSC takes its place. Curr Biol 12:R785-R787.

McGuire SE, Le PT, Osborn AJ, Matsumoto K, Davis RL (2003) Spatiotemporal rescue of memory dysfunction in Drosophila. Science 302:1765-1768.

O'Kusky JR, Ye P, D'Ercole AJ (2003) Increased expression of insulin-like growth factor I augments the progressive phase of synaptogenesis without preventing synapse elimination in the hypoglossal nucleus. J Comp Neurol 464:382-391.

Oldham S, Hafen E (2003) Insulin/IGF and target of rapamycin signaling: a TOR de force in growth control. Trends Cell Biol 13:79-85.

Packard M, Koo ES, Gorczyca M, Sharpe J, Cumberledge S, Budnik V (2002) The Drosophila Wnt, wingless, provides an essential signal for pre- and postsynaptic differentiation. Cell 111:319-330.

Radimerski T, Montagne J, Rintelen F, Stocker H, van der Kaay J, Downes CP, Hafen E, Thomas G (2002) dS6K-regulated cell growth is dPKB/ dPI(3)K-independent, but requires dPDK1. Nat Cell Biol 4:251-255.

Ramsey MM, Adams MM, Ariwodola OJ, Sonntag WE, Weiner JL (2005) Functional characterization of des-IGF-1 action at excitatory synapses in the CA1 region of rat hippocampus. J Neurophysiol 94:247-254.

Renn SC, Armstrong JD, Yang M, Wang Z, An X, Kaiser K, Taghert PH (1999) Genetic analysis of the Drosophila ellipsoid body neuropil: organization and development of the central complex. J Neurobiol 41:189-207.

Rico B, Beggs HE, Schahin-Reed D, Kimes N, Schmidt A, Reichardt LF (2004) Control of axonal branching and synapse formation by focal adhesion kinase. Nat Neurosci 7:1059-1069.

Rivlin PK, St. Clair RM, Vilinsky I, Deitcher DL (2004) Morphology and molecular organization of the adult neuromuscular junction of Drosophila. J Comp Neurol 468:596-613.

Rosenzweig ES, Barnes CA (2003) Impact of aging on hippocampal function: plasticity, network dynamics, and cognition. Prog Neurobiol 69:143-179.

Ruiz-Canada C, Ashley J, Moeckel-Cole S, Drier E, Yin J, Budnik V (2004) New synaptic bouton formation is disrupted by misregulation of microtubule stability in aPKC mutants. Neuron 42:567-580.
Sanchez S, Sayas CL, Lim F, Diaz-Nido J, Avila J, Wandosell F (2001) The inhibition of phosphatidylinositol-3-kinase induces neurite retraction and activates GSK3. J Neurochem 78:468-481.

Scheff SW, Price DA (2003) Synaptic pathology in Alzheimer's disease: a review of ultrastructural studies. Neurobiol Aging 24:1029-1046.

Schivell AE, Mochida S, Kensel-Hammes P, Custer KL, Bajjalieh SM (2005) SV2A and SV2C contain a unique synaptotagmin-binding site. Mol Cell Neurosci 29:56-64.

Schratt GM, Nigh EA, Chen WG, Hu L, Greenberg ME (2004) BDNF regulates the translation of a select group of mRNAs by a mammalian target of rapamycin-phosphatidylinositol 3-kinase-dependent pathway during neuronal development. J Neurosci 24:7366-7377.

Schubert M, Gautam D, Surjo D, Ueki K, Baudler S, Schubert D, Kondo T, Alber J, Galldiks N, Kustermann E, Arndt S, Jacobs AH, Krone W, Kahn CR, Bruning JC (2004) Role for neuronal insulin resistance in neurodegenerative diseases. Proc Natl Acad Sci USA 101:3100-3105.

Song J, Wu L, Chen Z, Kohanski RA, Pick L (2003) Axons guided by insulin receptor in Drosophila visual system. Science 300:502-505.

Spires TL, Hyman BT (2004) Neuronal structure is altered by amyloid plaques. Rev Neurosci 15:267-278.

Stocker H, Radimerski T, Schindelholz B, Wittwer F, Belawat P, Daram P, Breuer S, Thomas G, Hafen E (2003) Rheb is an essential regulator of S6K in controlling cell growth in Drosophila. Nat Cell Biol 5:559-565.

Strauss R (2002) The central complex and the genetic dissection of locomotor behaviour. Curr Opin Neurobiol 12:633-638.

Vicario-Abejon C, Yusta-Boyo MJ, Fernandez-Moreno C, de Pablo F (2003) Locally born olfactory bulb stem cells proliferate in response to insulinrelated factors and require endogenous insulin-like growth factor-I for differentiation into neurons and glia. J Neurosci 23:895-906.

Wagh DA, Rasse TM, Asan E, Hofbauer A, Schwenkert I, Durrbeck H, Buchner S, Dabauvalle MC, Schmidt M, Qin G, Wichmann C, Kittel R, Sigrist SJ, Buchner E (2006) Bruchpilot, a protein with homology to ELKS/ CAST, is required for structural integrity and function of synaptic active zones in Drosophila. Neuron 49:833-844.

Watts RJ, Schuldiner O, Perrino J, Larsen C, Luo L (2004) Glia engulf degenerating axons during developmental axon pruning. Curr Biol 14:678-684.

Zhao W, Chen H, Xu H, Moore E, Meiri N, Quon MJ, Alkon DL (1999) Brain insulin receptors and spatial memory. Correlated changes in gene expression, tyrosine phosphorylation, and signaling molecules in the hippocampus of water maze trained rats. J Biol Chem 274:34893-34902. 